\title{
Caspase-1 as a radio- and chemo-sensitiser in vitro and in vivo
}

\author{
PILAR MARTÍN-DUQUE ${ }^{1,2}$, MIGUEL QUINTANILLA ${ }^{3}$, IAIN MCNEISH ${ }^{1}$, RITA LOPES ${ }^{1}$, JESÚS ROMERO ${ }^{4}$, \\ DIANA ROMERO ${ }^{3}$, NICK R. LEMOINE ${ }^{1}$, SANTIAGO RAMÓN Y CAJAL ${ }^{5}$ and GEORGES VASSAUX ${ }^{1}$ \\ ${ }^{1}$ Cancer Research-UK Molecular Oncology Unit, Bart's and The London School of Medicine and Dentistry, \\ John Vane Science Centre, Charterhouse Square, London EC1M 6BQ, UK; ${ }^{2}$ Facultad de Ciencias Biosanitarias, \\ Universidad Francisco de Vitoria, Ctra. Pozuelo-Majadahonda, Km 1,800, Pozuelo de Alarcón, 28223 Madrid; \\ ${ }^{3}$ Instituto de Investigaciones Biomedicas, C.S.I.C, c/ Arturo Duperier 4, 28029 Madrid; ${ }^{4}$ Departamento Radioterapia, \\ Hospital Puerta de Hierro, c/ San Martín de Porres 4, 28035 Madrid; ${ }^{5}$ Departamento Anatomía Patológica, \\ Hospital Vall d'Hebron, Paseo Vall d'Hebron, 119-129, 08035 Barcelona, Spain
}

Received December 6, 2005; Accepted January 30, 2006

\begin{abstract}
The cytotoxic effect of anticancer drugs has been shown to involve induction of apoptosis. This observation raises the possibility that factors affecting caspase activation might be important determinants of anticancer drug sensitivity. Ectopic expression of caspase-1 has been shown to trigger apoptosis. However, the role of caspase- 1 in apoptosis is now considered as minor compared to other caspases. In patients, high levels of caspase- 1 expression may be associated with spontaneous regression in neuroblastomas and with a good clinical response to chemotherapy in acute myeloid leukemia and osteosarcoma. In experimental therapeutics for cancer, caspase- 1 has been related to some anticancer activity. These observations led us to examine the effect of over-expression on the response to chemotherapy and radiotherapy in vitro and in vivo. Caspase-1 expression mediated by an adenoviral vector was able to kill directly cells and to sensitise the remaining cells to cisplatin or $\gamma$-radiation in vitro. In HeLa cells stably transfected with caspase-1, sensitisation to cisplatin was due to an amplification of the cisplatin-induced mitochondrial apoptotic pathway activation. Caspase-1 mediated sensitisation to cisplatin and $\gamma$-radiation was also observed in vivo. Altogether, we conclude that caspase-1 can act as a radio- and chemo-sensitiser, in vitro and in vivo.
\end{abstract}

\section{Introduction}

Apoptosis can be initiated by a variety of stimuli, including growth factors, UV, $\gamma$-irradiation, or chemotherapeutic drugs.

Correspondence to: Dr Pilar Martín-Duque, Departamento de Biotecnología, Universidad Francisco de Vitoria, Ctra. PozueloMajadahonda, Km 1,800, Pozuelo de Alarcón, 28223 Madrid, Spain E-mail:p.martin@ufv.es

Key words: caspases, sensitisation, chemotherapy, radiotherapy, gene therapy
This phenomenon is co-ordinated by a family of cysteine proteases, the caspases. They mediate proteolysis of certain target proteins that ultimately result in cell death. There are two major intracellular caspase cascades: one activated predominately by death receptor ligands and the other triggered by various cellular stresses, including DNA damage and microtubule disruption (1).

The cytotoxic effect of anticancer drugs has been shown to involve induction of apoptosis (2). This observation raises the possibility that factors affecting caspase activation and activity might be important determinants of anticancer drug sensitivity (3). For example, it has been demonstrated that inhibition of caspases was associated with resistance to chemotherapy in vivo (4). In particular, apoptosis induced in tumour cells by cytarabine, doxorubicin, methatrexate (5), cisplatin (6), ionizing radiation (7) or taxotere (8) required the activation of caspase- 1 and -3 for induction of cell death.

Ectopic expression of caspase-1 has been shown to trigger apoptosis. However, the role of caspase-1 in apoptosis has been revisited and it is now considered minor compared to caspase- $3,-6,-7,-8,-9(1)$.

The potential of caspase- 1 in experimental therapeutics for cancer has been demonstrated: ICE was delivered by recombinant retrovirus (9), adenovirus (10) or via a gene gun (11).

In clinical studies, it has been suggested that caspase-1 may be associated with spontaneous regression of neuroblastomas (12). In addition, the correlation between the level of caspase- 1 expression and the response to chemotherapy appears to depend on the type of cancer studied. In acute myeloid leukemia (13), and osteosarcoma (14), high expression of caspase- 1 is correlated with a good clinical response to chemotherapy while high levels of serum caspase-1 are associated with non-response to biochemotherapy in melanoma (15).

These apparently conflicting data, as well as the potential of caspase- 1 as a therapeutic target, led us to examine the effect of caspase-1 over-expression on its own and in combination with chemotherapy and radiotherapy in a panel of cell lines. 


\section{Materials and methods}

Plasmids. Caspase-1 cDNA was amplified by PCR with the following set of primers (forward primer: 5'-CGGGGTACC CCATGGCCGACAAGGTCCTG-3' and reverse primer: 5'CTAGTCTAGATGCCCACAGACATTC-3') using the ICEpBluescript vector (kindly gived by Dr Fueyo) as a template. The PCR product was cloned into pEF6/V5-His-TOPO vector (Invitrogen, UK) and sequenced. One clone with the cDNA inserted in the correct orientation was chosen. In transfection experiments, an empty pEF6/V5-His-TOPO vector was used as a control.

The caspase-1 cDNA was inserted into the EcoRV/KpnI sites of pShuttle (16) to generate pSh-ICE. Once linearised with PmeI, pSh-ICE was then recombined with pAdeasy 1 as previously described to generate pAd-ICE. Correct recombinants were selected by restriction endonuclease digestion.

Adenoviral vectors. Ad-GFP, was obtained from Qbiogene (Cambridge, UK), and Ad-Mock was an E1-deleted Ad-5 vector containing no transgene (17). The virus Ad-ICE was generated after transfection of pAd-ICE into 293 cells. It was produced, purified and titrated as previously described (18).

Cell lines. Cervical carcinoma cell line HeLa, pancreatic cell lines Panc-O2, HPAF and Panc-1 and the human prostate cancer cell lines DU-145, PC-3, BHP-1, LNCaP, were obtained from the Research Cell Service of Cancer Research-UK. Cells were grown on DMEM or RPMI-1640 medium containing $10 \%$ fetal bovine serum in presence of antibiotics.

HeLa cells $\left(10^{5}\right)$ per well, were transfected with $0.4 \mu \mathrm{g}$ of DNA in 6-well plates using Effectene transfection reagent (Qiagen, UK), according to the manufacturer's protocols with minor modifications, in order to construct HeLa-Topo and $\mathrm{HeLa}-\mathrm{ICE}$ cell lines. Blasticidin $\mathrm{S} \mathrm{HCl}$ (Invitrogen) resistant clones, were selected at doses of $10 \mu \mathrm{g} / \mathrm{ml}$.

Caspase-1 enzymatic assay. p45-proICE is found in normal HeLa cells but does not form the active protease (19). Caspase-1 enzymatic activity was assayed using the caspase-1/ ICE Colorimetric Protease Assay kit (MBL, Japan) according to the manufacturer's instructions, based on the cleavage of the YVAD-pNA substrate in the presence or absence of the caspase-1 selective inhibitor YVAD-FMK.

In vitro cytotoxicity assay. Cell lines $\left(2 \times 10^{4}\right.$ cells $)$, were plated onto 24-well plates with $1 \mathrm{ml}$ of DMEM with $10 \%$ serum, with the only exception of the radiation experiments where $10^{3}$ cells per well were seeded. Twenty-four hours later, cells were infected with 1-10 p.f.u. per cell, and the next day, different concentrations of cisplatin (Sigma-Aldrich, UK), paclitaxel (Taxol, Calbiochem, CA), or $\gamma$-radiation were administered. For experiments on HeLa-Topo or HeLa-ICE, the treatment started $24 \mathrm{~h}$ after seeding of the cells. Five or seven days (for irradiation experiments) after the treatment started, $100 \mu \mathrm{l}$ of MTT was added $(5 \mathrm{mg} / \mathrm{ml})$ (Sigma-Aldrich). The cells were incubated for $2 \mathrm{~h}$ at $37^{\circ} \mathrm{C}$, dissolved in DMSO and the optical density at $540 \mathrm{~nm}$ was measured.

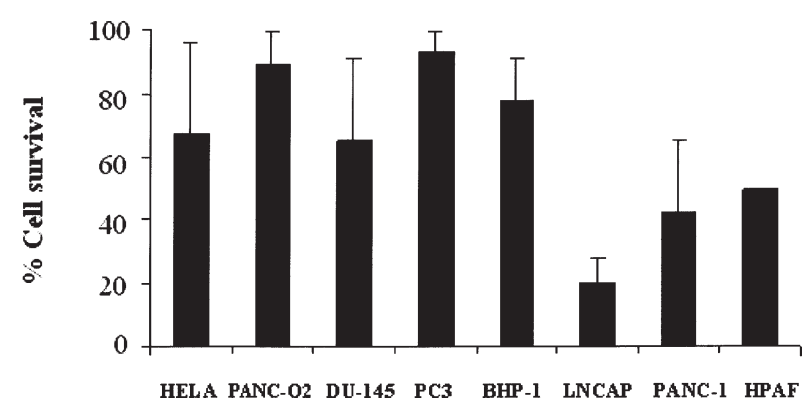

Cell lines

Figure 1. Effect of Ad-ICE infection on cell viability. Cells $\left(2 \times 10^{4}\right)$, were plated onto 24-well plates and allowed to growth $24 \mathrm{~h}$ before infected with Ad-ICE or Ad-Mock in a range of doses between 1-10 plaque-forming units (p.f.u.) per cell. For each cell line, the dose of virus used was enough to infect $100 \%$ of the cells. Cell viability was measured 5 days post-infection by MTT assay. The $\%$ of cell survival is the $\%$ of the number of live cells infected by Ad-ICE related to the number of live cells after infection with Ad-Mock. Each experiment was performed in triplicate.

Flow cytometry. HeLa-Topo or HeLa-ICE cells $\left(10^{6}\right)$ were plated onto 6-cm diameter dishes and treated with cisplatin $(1 \mu \mathrm{g} / \mathrm{ml})$. At different times, cells were washed with PBS, and harvested. Protocol was followed as previously described (17), and samples were passed through a filter cap immediately prior to analysis on a FACSCalibur ${ }^{\mathrm{TM}}$ (Beckton-Dickinson).

Western blots. HeLa-Topo or HeLa-ICE cells $\left(10^{6}\right)$ were plated onto 6-cm diameter tissue culture dishes. The next day, cells were treated with $0,0.3$ or and $1 \mu \mathrm{g} / \mathrm{ml}$ of cisplatin and collected after $18 \mathrm{~h}$ of treatment. Cells and supernatant were pelleted, and $100 \mu 1$ of lysis buffer $(150 \mathrm{~mm} \mathrm{NaCl}, 50 \mathrm{mM}$ Tris $\mathrm{pH} 7.5,0.05 \%$ SDS, $1 \%$ Triton $\mathrm{X}-100)$ was added. The resulting homogenate was sonicated on ice.

Protein extract $(20 \mu \mathrm{g})$ was separated on 10-15\% SDSpolyacrylamide gels and transferred onto nitrocellulose filters by semidry blotting. The primary antibodies used were mouse monoclonals anti-PARP IgG (1:2000) (Santa Cruz) and anti-caspase $8 \mathrm{IgG}$ (1:1000) (Alexis Biochemicals, UK), a rabbit polyclonal anti-caspase-9 (1:500) (Santa Cruz, UK), and mouse monoclonal anti-GFP 3E1 (1:4000) (Cancer Research-UK Monoclonal Antibody Services). Secondary antibodies were a rabbit anti-mouse $(1: 1500)$ or a goat antirabbit $(1: 1500)$ HRP conjugated from Sigma. Antibody binding was visualized using ECL (Amersham Pharmacia Biotech, UK).

Real-time PCR. HeLa Topo or HeLa-ICE cells $\left(10^{6}\right)$ were plated onto $6-\mathrm{cm}$ diameter tissue culture dishes. The next day, cells were treated with $0,0.3,0.5$ or $1 \mu \mathrm{g} / \mathrm{ml}$ cisplatin and collected after $18 \mathrm{~h}$ of treatment. RNA was extracted using TRIzol (Invitrogen) according to the manufacturer's protocol. Total RNA was resuspended in $100 \mu 1$ RNAse-free water and RNA $(2 \mu \mathrm{g})$ was reverse transcribed using TaqMan reverse transcription reagents kit (ABI), as previously described (20).

Forward and reverse primers for cIAP-1, cIAP-2, XIAP and PGK-1 (endogenous control) were designed using Primer express software and used at a concentration of $300 \mathrm{~nm} /$ 

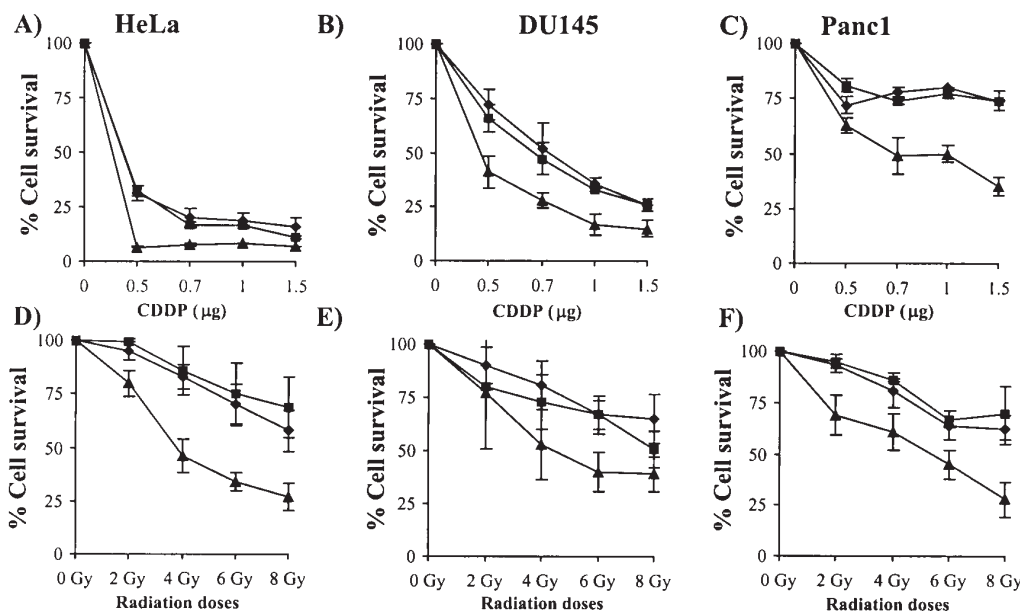

Figure 2. Effect of Ad-ICE infection on radio- and chemo-sensitization in vitro: $2 \times 10^{4}$ cells ( $10^{3}$ cells per well for irradiation experiments), were plated onto 24-well plates and allowed to growth $24 \mathrm{~h}$ before infected with Ad-ICE or Ad-Mock in a range of doses between 1-10 plaque-forming units (p.f.u.) per cell. For each cell line, the dose of virus used was enough to infect $100 \%$ of the cells. The day after infection cells were treated with cisplatin (A-C) or radiotherapy (D-F) and 5 (for CDDP) or 7 days (for radiotherapy) after treatment, cell viability was measured by MTT. Experiments were performed in triplicate for each cell line and treatment. The data presented are the mean \pm SD of three experiments performed in triplicate wells. Diamond, uninfected; square, mock-infected; triangle, ICE-infected cell line.

$300 \mathrm{~nm}$. The sequences of the primers used are: cIAP1, TGTTGTCAACTTCAGATACCACTGG/CATCATGACAG CATCTTCTGAAGA; cIAP2, GGACAGGAGTTCATCCG TCAAG/TGGATAATTGATGACTCTGCATTTTC; XIAP, GACAGTATGCAAGATGAGTCAAGTCA/GCAAAGCTT CTCCTCTTGCA; PGK-1, TGGAGAACCTCCGCTTTCAT/ TGGCTCGGCTTTAACCTTGT.

In vivo studies. HeLa-Topo or HeLa-ICE cells $\left(10^{6}\right)$ were injected subcutaneously into 6-week-old female Balb/c nude mice. Experiments were conducted after appropriate local ethical approval. Nude mice were obtained from Harlan Iberica (Barcelona, Spain) and were kept in a germ-free environment with irradiated food and acidified water ad libitum. When a tumour reached $0.2 \mathrm{~cm}^{2}$, groups of mice received a single intraperitoneal injection of cisplatin (Bristol-Myers-Squibb) of $1,4,7$ or $10 \mathrm{mg} / \mathrm{kg}$ of weight, or PBS injection for controls.

For radiotherapy experiments, treated mice received semicorporal irradiation in an AECL Cobalt unit, at a skin surface distance of $80 \mathrm{~cm}$ and a radiation coefficient of $136 \mathrm{cGy} / \mathrm{min}$. They received daily doses of $600 \mathrm{cGy}$ up to a total of $12 \mathrm{~Gy}$. The upper body was covered and the fractioning of the irradiation was chosen to minimize the toxicity produced by the irradiation. Tumour size was determined by two perpendicular measurements every other day, until the tumour size reached the limit authorised by the local ethical approval.

\section{Results}

Expression of caspase-1 mediated by an adenoviral vector in cell lines of different origins. Immunohistochemical studies showed that the majority of primary prostate cancer cells lacked caspase-1 protein expression compared with normal prostatic tissue (21) but on the contrary, over-expression of caspase- 1 is observed in most of pancreatic cancer cells compared with normal pancreatic tissue (22).
In order to assess whether the responses to caspase-1 were tumour type-specific, we infected a panel of prostatic (DU-145, PC-3, BHP-1 or LNCaP), pancreatic (Panc-O2, Panc-1, HPAF) and cervical (HeLa) carcinoma cell lines with an adenovirus encoding caspase-1. For each cell line, the dose of virus used was determined by Ad-GFP which ensured $100 \%$ cell transfection without non-specific viral toxicity (data not shown).

Infection with Ad-ICE produced a marked decrease of survival in most of the cell lines 3 days after infection, compared with uninfected control (data not shown) or with an identical adenovirus without caspase-1 expression (Fig. 1). These results were observed on all the cell lines tested, but even in the most sensitive cell line ( $\mathrm{LNCaP})$, some cells resistant to caspase-1 remained (Fig. 1).

Adenoviral expression of caspase-1 sensitises cells to anticancer treatments in vitro. To test the radio or chemosensitization produced by ICE over-expression after adenoviral infection, various cell lines were incubated for 5 or 7 days with several doses of cisplatin or $\gamma$-radiation.

Fig. 2 shows that the extent of the effect of $\gamma$-radiation or cisplatin depends on the cell line studied. However, all cells infected with Ad-ICE showed a marked sensitization to different treatments compared with non-infected cells or infected with mock adenovirus.

Generation of a cell line over-expressing caspase-1. To examine further the effect of radio and chemotherapy on cells not sensitive to caspase- 1 action, a HeLa cell line overexpressing caspase-1 was generated.

The presence of the caspase- 1 cDNA in the genome of HeLa-ICE cells was detected by PCR on genomic DNA and was absent from the control line HeLa-Topo (data not shown). Caspase-1 activity was measured on HeLa-Topo and HeLaICE cells treated with $0.3 \mu \mathrm{g} / \mathrm{ml}$ of cisplatin (CDDP). The specific enzymatic activities were 0.06 absorbance units/mg 
A)

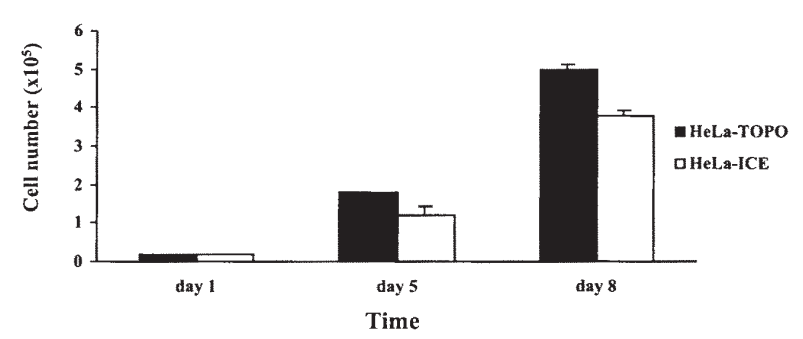

B)

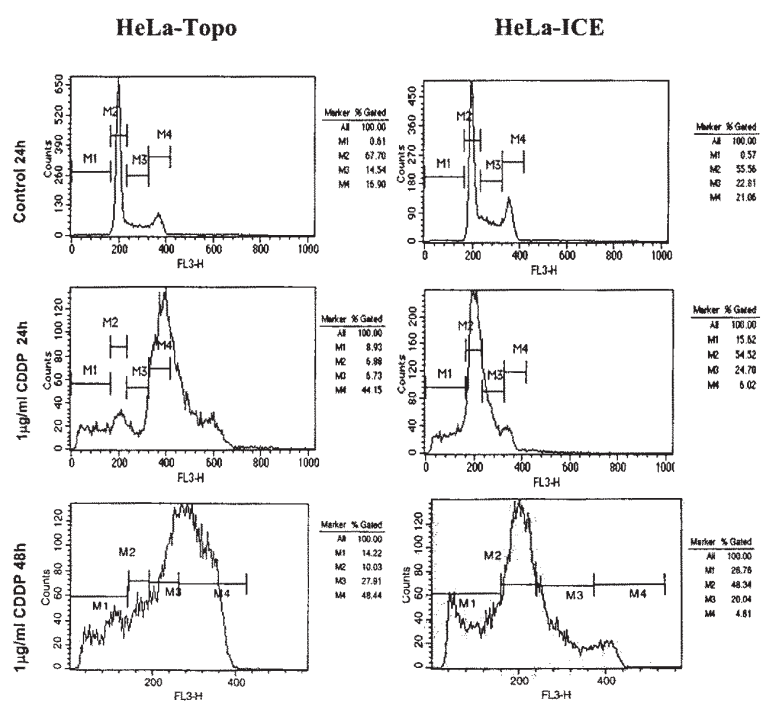

Figure 3. Effect of caspase-1 over-expression on the growth potential of HeLa cells. (A) HeLa-Topo (black bars) or HeLa-ICE (white bars) cells $\left(2 \times 10^{4}\right)$ were seeded in 24-well plates under standard conditions. Triplicated wells for each condition were counted on days 1,5 and 8 . The cells reached confluency on day 10 . The data presented are the mean \pm SD of three experiments per-formed. (B) Flow cytometry analysis. HeLa-Topo or HeLaICE cells $\left(10^{6}\right)$ were treated or not (control) with $1 \mu \mathrm{g} / \mathrm{ml}$ cisplatin. Twentyfour or $48 \mathrm{~h}$ later, cells were trypsinized, fixed in ethanol and stained with propidium iodide before to be analysed on a FACSCalibur ${ }^{\mathrm{TM}}$. The tables next to each figure show the percentage of cells in each phase of the cell cycle. M1, sub-G1 population; M2, G0/G1 population; M3, S population; $\mathrm{M} 4, \mathrm{G} 2 / \mathrm{M}$.

of protein for HeLa-Topo and 0.21 absorbance units/mg of protein for HeLa-ICE.

To compare their growth potential, both cell lines were seeded on day 0 and the number of cells was evaluated at days 1,5 and 8 . Fig. 3A shows that HeLa-ICE cells in vitro grow significantly more slowly than the control HeLa-Topo. To determine whether this difference is due to delayed cell cycle or concomitant cell growth and death of the HeLa-ICE cells, flow cytometry analysis of both cell lines was performed (Fig. 3B). No significant difference in the sub-G1 population (an indicator of apoptosis) was observed in untreated HeLaTopo and HeLa-ICE cells (Fig. 3B). By contrast, the number of cells in G2/M (M4) and S phase (M3) was significantly increased in HeLa-ICE cells (Fig. 3B). The difference in cell number observed in Fig. 3A is therefore likely to be the result of a caspase-1-mediated delayed cell cycle.

Caspase-1 over-expression sensitises HeLa cells to $\gamma$-radiation, in vitro. To assess the effect of caspase- 1 over-expression on the cell death induced by $\gamma$-radiation, HeLa-ICE or HeLaTopo cells were subjected to various doses of irradiation. Fig. 4A shows that $\gamma$-radiation can kill HeLa-Topo cells, in a
A)

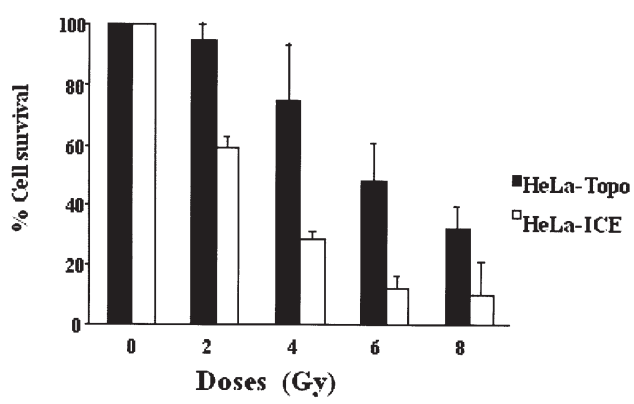

B)
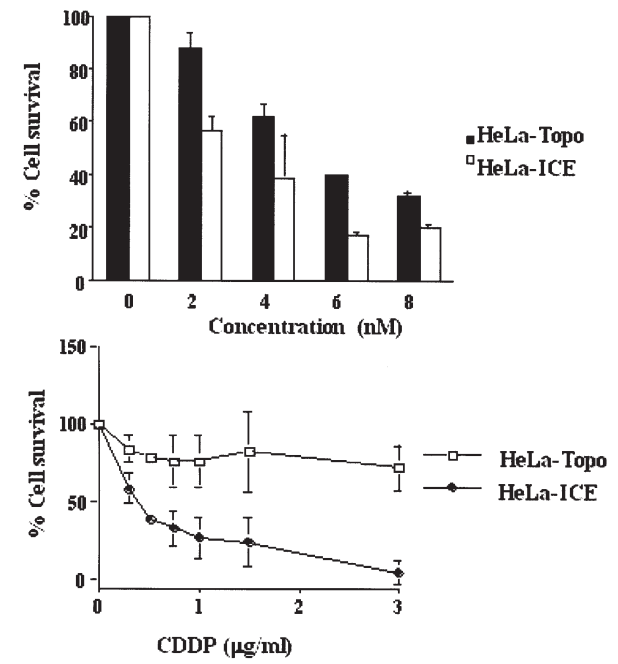

Figure 4. Effect of treatments on HeLa-Topo or HeLa-ICE cells. (A) $\gamma$ radiation: HeLa-Topo (black bars) or HeLa-ICE cells (white bars) $\left(10^{3}\right)$ were seeded in a 24-well plate. Twenty-four hours later, cells were subjected to different doses of $\gamma$-irradiation (see graph). (B and C) Chemotherapeutic agents: HeLa-Topo (black bars) or HeLa-ICE cells (white bars) $\left(2 \times 10^{4}\right)$ were treated with different concentrations of Taxol (B) or cisplatin (C). Five days after the beginning of the treatment (or 7 for $\gamma$-radiation) the number of viable cells was determined using an MTT assay. For each cell line, 100\% correspond to the number of cells non-treated. The data presented are the mean $\pm \mathrm{SD}$ of three experiments performed in triplicate.

dose-dependent manner. This toxic effect was enhanced in HeLa-ICE cells. This sensitisation is particularly observed at a low radiation dose $(2 \mathrm{~Gy})$, sufficient to induce the death of around half of the HeLa-ICE population, while HeLa-Topo cells remained largely unaffected (Fig. 4A).

Caspase-1 over-expression sensitises HeLa cells to chemotherapeutic agents in vitro. The effect of caspase-1 overexpression on the cell death induced by Taxol was examined by incubating HeLa-ICE or HeLa-Topo cells with various concentrations of the drug for 5 days. Fig. 4B shows a dosedependent decrease in cell survival of the treated cells, with a modest but significant increased sensitivity of HeLa-ICE to Taxol.

By contrast, when these experiments were repeated with cisplatin (CDDP), a dose-dependent decrease in cell survival was observed with doses of cisplatin as low as $0.5 \mu \mathrm{g} / \mathrm{ml}$, with the entire population of HeLa-ICE cells being killed with a dose of $3 \mu \mathrm{g} / \mathrm{ml}$. This effect was accompanied by an increase in the sub-G1 population, 24 and $48 \mathrm{~h}$ after the start of the treatment with $1 \mu \mathrm{g} / \mathrm{ml}$ of cisplatin (Fig. 3B). These data suggest that the increased sensitisation to cisplatin mediated by caspase- 1 involves enhancement of apoptosis. 
A)

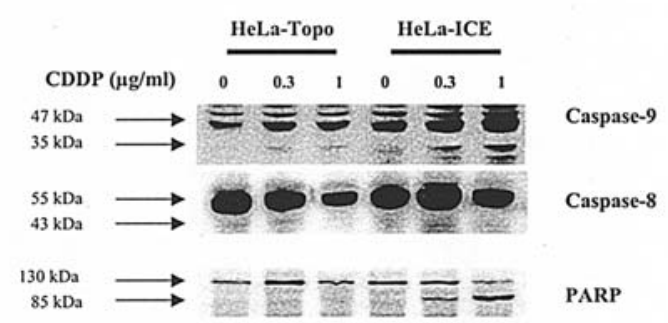

B)

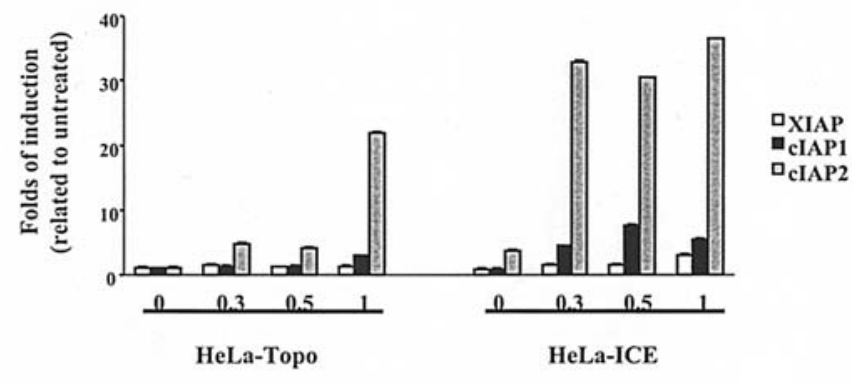

Figure 5. Caspase and IAP analysis on HeLa-Topo and HeLa-ICE cell lines. (A) Western blot analysis of HeLa-Topo and HeLa cell lines treated with cisplatin. HeLa-Topo or HeLa-ICE cells $\left(10^{6}\right)$ were plated onto 6-cm diameter tissue culture dishes, treated the next day with different doses of cisplatin (see figure) and collected after $18 \mathrm{~h}$ of treatment. Cells and supernatant were pelleted, lysed and sonicated on ice. Twenty micrograms of protein extract was separated on SDS-polyacrylamide gels and transferred onto nitrocellulose filters. Monoclonals for anti-PARP IgG, anti-caspase-8 IgG and a rabbit polyclonal for anti-caspase-9 were used. (B) Real-time PCR analysis of inhibitors of apoptosis in HeLa-Topo and HeLa-ICE cell lines. HeLa-Topo or HeLa-ICE cells $\left(10^{6}\right)$ were plated onto 6-cm diameter tissue culture dishes. The next day, the cells were treated with $0,0.3,0.5$ or $1 \mu \mathrm{g} / \mathrm{ml}$ cisplatin and collected after $18 \mathrm{~h}$ of treatment. RNA $(2 \mu \mathrm{g})$ was reversetranscribed to perform real-time PCR reactions for cIAP-1, cIAP-2, XIAP and PGK-1 (endo-genous control, data not shown). Samples from three separate experiments were analysed in triplicate.

Caspase-1 amplifies cisplatin-induced mitochondrial apoptotic pathway. In response to a pro-apoptotic stimulus involving cytochrome-C release from the mitochondria, the $47 \mathrm{kDa}$ procaspase-9 is cleaved into its small (12 kDa) and large (35 kDa) sub-units. Independently, activation of receptors mediating cell death (TNF-R1, TNF-R2, death receptor 3 and 4 or Fas) induce the activation of caspase- 8 which result in its proteolytic cleavage (1). Both apoptotic pathways will ultimately converge to the activation of effector caspases, such as caspase-3 that will cleave cellular proteins like the poly (ADP-ribose)-polymerase (PARP) that is cleaved into p85 and p25 proteins. Incubation of HeLa-Topo cells with 0.3 or $1 \mu \mathrm{g} / \mathrm{ml}$ of cisplatin led to a very modest cleavage of caspase-9 that did not result in a significant PARP-cleavage (Fig. 5A). By contrast, incubation of HeLa-ICE cells with cisplatin led to a dose-dependent activation of caspase-9 paralleled by a PARP-cleavage (Fig. 5A). Under similar treatment, caspase- 8 remained unaffected in both cell lines, indicating that caspase- 1 over-expression amplifies the cisplatin-induced mitochondrial apoptotic pathway, without affecting the ligand-induced apoptotic pathway. Interestingly,
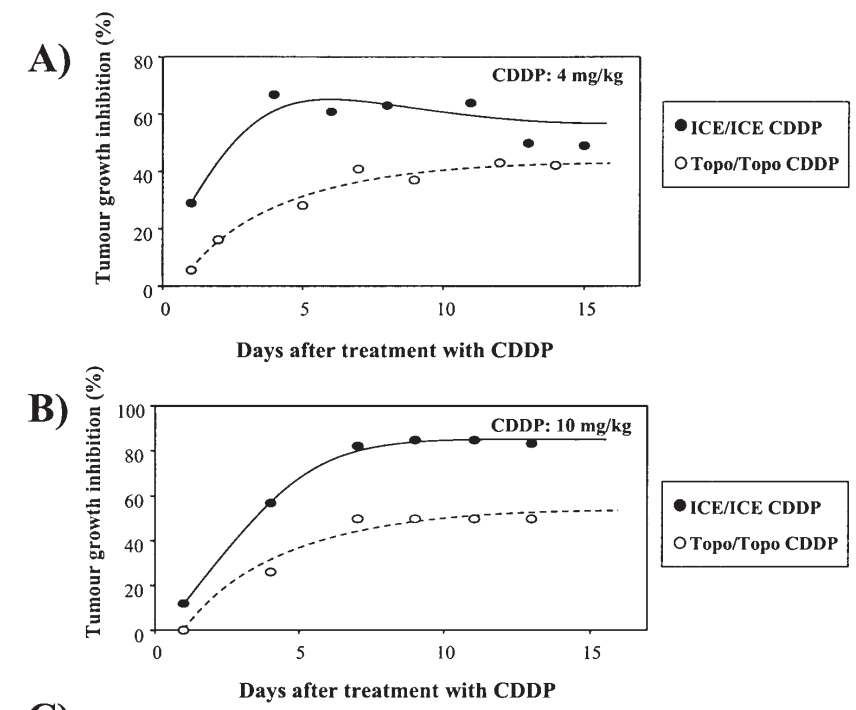

C)

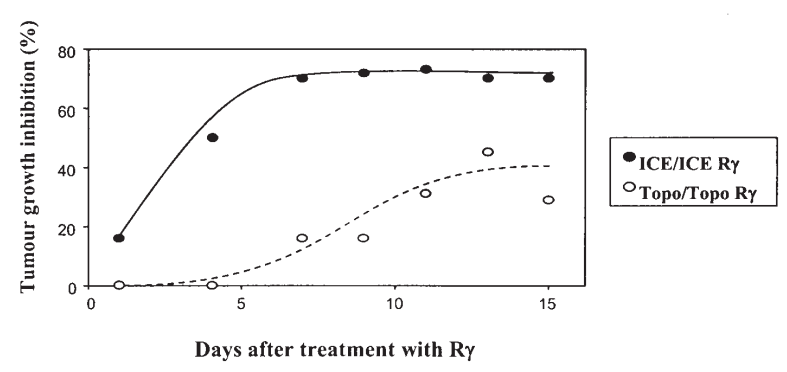

Figure 6. Effect of cisplatin and $\gamma$-radiation in HeLa-Topo and HeLa-ICE cells in vivo. One million HeLa-Topo or HeLa-ICE cells were injected subcutaneously into 6-week-old female Balb/c nu/nu mice. Tumours were treated (A and B) with cisplatin (CDDP) at doses of 4 or $10 \mathrm{mg} / \mathrm{kg}$ weight or PBS for the controls, or (C) with $\gamma$-radiation on 2 consecutive days (two doses leading to a total of $12 \mathrm{~Gy}$ ), when they reached approximately the size of $0.2 \mathrm{~cm}^{2}$. For both groups, the size at the start of the treatment was HeLaTopo $0.21 \pm$ SD: 0.05 and HeLa-ICE $0.2 \pm$ SD: 0.06, respectively. The tumour sizes were measured every other day. These values represent an average of at least 8 tumours. For each time point, the size of the tumour treated is divided by the size of the non-treated tumour and this result is multiplied by 100. This value is then substracted to $100 \%$ to obtain the tumour growth inhibition presented.

this effect on the apoptotic cascade was accompanied by an increase in the levels of transcripts of the inhibitors of apoptosis such as XIAP, cIAP1 and -2 (Fig. 5B).

Caspase-1 as a chemo- and radio-sensitiser in vivo. To determine whether the caspase-1-mediated sensitisation obtained in vitro (Fig. 4) could be observed in vivo, HeLaTopo or HeLa-ICE cells were injected subcutaneously in nude mice and the animals were treated with increasing doses of cisplatin (4 and $10 \mathrm{mg} / \mathrm{kg}$ weight) (Fig. 6A and B) or radiotherapy (Fig. 6C) when the tumours reached $0.2 \mathrm{~cm}^{2}$. In both experiments, we observed that HeLa-Topo tumours grew faster in vivo than HeLa-ICE tumours (data not shown), as suggested by their growth rate in vitro (Fig. 3A). Intraperitoneal administration of 4 or $10 \mathrm{mg} / \mathrm{kg}$ cisplatin led to an inhibition of tumour growth in HeLa-Topo tumours (Fig. 6A and B). This effect was dramatically increased when HeLaICE-bearing animals were subjected to the same treatment, with tumours reducing by $>90 \% 7$ days after a single administration of $10 \mathrm{mg} / \mathrm{kg}$ weight of cisplatin (Fig. 6B). In the same group $3 / 8$ tumours remained undetectable when the 
experiment was stopped. Dose-dependent response was obtained when doses of 1 and $7 \mathrm{mg} / \mathrm{kg}$ weight were injected (data not shown).

Similarly, two sessions of radiotherapy when the tumours reached around $0.2 \mathrm{~cm}^{2}$, on 2 consecutive days (to a total of $12 \mathrm{~Gy}$ ) led to a reduction in the rate of tumour growth in HeLaTopo-bearing animals (Fig. 6C). Greater tumour regression was observed when HeLa-ICE-bearing animals were subjected to the same treatment (Fig. 6C), with 3/8 tumours remaining undetectable when the experiment was stopped.

\section{Discussion}

In the present study, we report that over-expression of caspase- 1 by adenovirus is capable of killing a proportion of the cells infected. In addition, we show that the surviving cells expressing caspase- 1 have increased sensitivity to radiotherapy and chemotherapy in vitro. This sensitisation appeared to be quantitatively more important when DNA-damaging agents (as cisplatin and $\gamma$-radiation) were used as opposed to a drug affecting microtubules like Taxol. In the case of sensitisation to cisplatin, the effect of caspase- 1 is accompanied by an increase in mRNA levels of anti-apoptotic molecules such as XIAP and cIAP1 and cIAP2. Finally caspase-1 can sensitise HeLa cells to cisplatin or $\gamma$-radiation in vivo.

These data are in agreement with some clinical results associating caspase- 1 with a favourable response to chemotherapy: in acute myeloid leukemia, high expression of caspase-1 indicated a good clinical response to chemotherapy (13) or a favourable prognosis; high levels of caspase-1 have been correlated with spontaneous regression in neuroblastoma (12). Also, the serum concentration of caspase-1 in highgrade osteosarcoma patients has been shown to correlate with a good response to chemotherapy (14). Similarly, high levels of expression of caspase-1 observed in low-grade astroglial tumours were seen in apoptotic areas of the tumours and that was correlated with longer survival (23). An immunohistochemical study revealed that the majority of primary prostate cancer lacked caspase-1 immunoreactivity whereas the remaining showed reduced expression compared with normal prostate (21). This set of data suggests that caspase- 1 expression is probably negatively selected during the establishment of a primary prostate tumour.

By contrast, increased caspase- 1 expression has been associated with a poorer prognosis in other types of malignancy. In pancreatic cancer, over-expression of caspase- 1 is observed in a majority of cells, whereas normal pancreatic tissue shows only occasional immunoreactivity (22), suggesting an additional function of caspase- 1 besides apoptosis to promote pancreatic malignancy.

Several proteins have already been suggested as radioand/or chemo-sensitisers to cancer cells, some of them are currently being used in gene therapy clinical trials. In this respect, adenovirus-mediated delivery of $p 53$ tumour suppressor gene is the best-documented and multiple evidence suggest that alteration of p53 functions result in reduced responses to anticancer agents (24). Therefore, replacement therapy using p53, in combination with DNA-damaging agents is a strategy currently developed in a growing number of malignancies, for which local disease control remains sub-optimal. The adenovirus type $5 \mathrm{E} 1 \mathrm{~A}$ protein and some mutants generated from it were also shown to sensitise carcinoma cells to radio- and chemo-therapy in a p53independent manner in vitro and in vivo in murine and human tumour models (25).

Previous studies on some of the cell lines that we used in the present work, were employed to correlate the sensitivity or resistance of the different cell lines to anticancer treatments with genetic factors described in the literature (26). Some of these genetic pathways involved genes such as different members of the IAP family (cIAP1 and 2, XIAP), mutations in 553 , pro- and anti-apoptotic members of the Bcl-2 family (Bax, Bcl-2 or Bcl-xl), the androgen dependency or not, or the intrinsic status of caspase-1. Neither the kind of tumour or any of the studied factors, including caspase- 1 expression was correlated with the response showed by the cell lines to treatments.

Caspase- 1 has already demonstrated some effect in experimental therapeutics for cancer. Retroviral- (4) and adenoviral-mediated delivery (10) of caspase-1 induced apoptosis that correlated in vivo with an anti-tumour effect. Combined with our observations, these data demonstrate the potential of caspase-1 for cancer gene therapy protocols where caspase-1 gene delivery could be used in combination with chemotherapy or radiotherapy.

In conclusion, we propose to use caspase- 1 as a radioand chemo-sensitiser in cancer gene therapy protocols, possibly combining the vectors with tumour/tissue selective promoters to avoid the effect in other tissues. The tumour target would be ideally accessible and treatable by either or both types of agents. In this context, primary prostate cancer appears to be a suitable candidate disease as in addition to prostate selective promoters, caspase- 1 expression is lost (21). This local treatment of an accessible primary tumour site could be complemented by immunotherapy in which caspase- 1 could also be a key player interfering with the development of distant metastatic disease.

\section{Acknowledgements}

We are grateful to Mónica López-Barahona, Carlos Parada, Javier Hernandez, and Korin Knight for their assistance. Research in the laboratory of Georges Vassaux is supported by Cancer Research-UK, Royal Society-CSIC and Pilar MartínDuque by Programa Ramón y Cajal del Ministerio de Educación y Ciencia Español and Universidad Francisco de Vitoria.

\section{References}

1. Abraham MC and Shaham S: Death without caspases, caspases without death. Trends Cell Biol 14: 184-193, 2004.

2. Kaufmann SH and Earnshaw WC: Induction of apoptosis by cancer chemotherapy. Exp Cell Res 256: 42-49, 2000.

3. Mow BM, Blajeski AL, Chandra J and Kaufmann SH: Apoptosis and the response to anticancer therapy. Curr Opin Oncol 13: 453-462, 2001.

4. Hara S, Miyake H, Arakawa S, Kamidono S and Hara I: Overexpression of inhibitor of caspase 3 activated deoxyribonuclease in human renal cell carcinoma cells enhances their resistance to cytotoxic chemotherapy in vivo. J Urol 166: 2491-2494, 2001.

5. Los M, Herr I, Friesen C, Fulda S, Schulze-Osthoff K and Debatin KM: Cross-resistance of CD95- and drug-induced apoptosis as a consequence of deficient activation of caspases (ICE/Ced-3 proteases). Blood 90: 3118-3129, 1997. 
6. Hara S, Miyake H, Arakawa S, Kamidono S and Hara I: Cisplatinresistant HeLa cells are resistant to apoptosis via p53-dependent and -independent pathways. Jpn J Cancer Res 90: 1373-1379, 1999.

7. Ferrer I: Role of caspases in ionizing radiation-induced apoptosis in the developing cerebellum. J Neurobiol 41: 549$558,1999$.

8. Suzuki A, Kawabata T and Kato M: Necessity of interleukin1 beta converting enzyme cascade in taxotere-initiated death signaling. Eur J Pharmacol 343: 87-92, 1998.

9. Yu JS, Sena-Esteves M, Paulus W, Breakefield XO and Reeves SA: Retroviral delivery and tetracycline-dependent expression of IL-1beta-converting enzyme (ICE) in a rat glioma model provides controlled induction of apoptotic death in tumor cells. Cancer Res 56: 5423-5427, 1996.

10. Shariat SF, Desai S, Song W, Khan T, Zhao J, Nguyen C, et al: Adenovirus-mediated transfer of inducible caspases: a novel 'death switch' gene therapeutic approach to prostate cancer. Cancer Res 61: 2562-2571, 2001.

11. Oshikawa K, Shi F, Rakhmilevich AL, Sondel PM, Mahvi DM and Yang NS: Synergistic inhibition of tumor growth in a murine mammary adenocarcinoma model by combinational gene therapy using IL-12, pro-IL-18, and IL-1beta converting enzyme cDNA. Proc Natl Acad Sci USA 96: 13351-13356, 1999.

12. Ikeda H, Nakamura Y, Hiwasa T, Sakiyama S, Kuida K, Su MS, et al: Interleukin-1 beta converting enzyme (ICE) is preferentially expressed in neuroblastomas with favourable prognosis. Eur $\mathbf{J}$ Cancer 33: 2081-2083, 1997.

13. Stoetzer OJ, Nussler V, Darsow M, Gullis E, Pelka-Fleischer R, Scheel U, et al: Association of bcl-2, bax, bcl-xL and interleukin-1 beta-converting enzyme expression with initial response to chemotherapy in acute myeloid leukemia. Leukemia 10 (Suppl 3): S18-S22, 1996

14. Holzer G, Trieb K, Koschat M, Blahovec H and Kotz R: Serum concentrations of APO-1/Fas and interleukin-1beta-converting enzyme in osteosarcoma correlate with response to chemotherapy. Anticancer Res 22: 1869-1872, 2002.

15. Mouawad R, Antoine EC, Gil-Delgado M, Khayat D and Soubrane C: Serum caspase-1 levels in metastatic melanoma patients: relationship with tumour burden and non-response to biochemotherapy. Melanoma Res 12: 343-348, 2002.

16. He TC, Zhou S, Da Costa LT, Yu J, Kinzler KW and Vogelstein B: A simplified system for generating recombinant adenoviruses. Proc Natl Acad Sci USA 95: 2509-2514, 1998.
17. McNeish IA, Tenev T, Bell S, Marani M, Vassaux G and Lemoine N: Herpes simplex virus thymidine kinase/ ganciclovir-induced cell death is enhanced by co-expression of caspase-3 in ovarian carcinoma cells. Cancer Gene Ther 8: 308-319, 2001.

18. Martin-Duque P, Jezzard S, Kaftansis L and Vassaux G: Direct comparison of the insulating properties of two genetic elements in an adenoviral vector containing two different expression cassettes. Hum Gene Ther 15: 995-1002, 2004.

19. Shi L, Chen G, MacDonald G, Bergeron L, Li H, Miura M, et al: Activation of an interleukin 1 converting enzyme-dependent apoptosis pathway by granzyme B. Proc Natl Acad Sci USA 93: 11002-11007, 1996.

20. Pardo OE, Lesay A, Arcaro A, Lopes R, Ng BL, Warne PH, et al: Fibroblast growth factor 2-mediated translational control of IAPs blocks mitochondrial release of Smac/DIABLO and apoptosis in small cell lung cancer cells. Mol Cell Biol 23: 7600-7610, 2003.

21. Winter RN, Kramer A, Borkowski A and Kyprianou N: Loss of caspase-1 and caspase-3 protein expression in human prostate cancer. Cancer Res 61: 1227-1232, 2001.

22. Ramadani M, Yang Y, Gansauge F, Gansauge S and Beger HG: Overexpression of caspase-1 (interleukin-1beta converting enzyme) in chronic pancreatitis and its participation in apoptosis and proliferation. Pancreas 22: 383-387, 2001.

23. Ehrmann J Jr, Rihakova P, Hlobilkova A, Kala M and Kolar Z: The expression of apoptosis-related proteins and the apoptotic rate in glial tumors of the brain. Neoplasma 47: 151-155, 2000.

24. Kirsch DG and Kastan MB: Tumor-suppressor p53: implications for tumor development and prognosis. J Clin Oncol 16: 3158-3168, 1998

25. Martin-Duque P, Sanchez-Prieto R, Romero J, MartinezLamparero A, Cebrian-Sagarriga S, Guinea-Viniegra J, et al: In vivo radiosensitizing effect of the adenovirus E1A gene in murine and human malignant tumors. Int J Oncol 15: 1163-1168, 1999.

26. Van Brussel JP, van Steenbrugge GJ, Romijn JC, Schroder FH and Mickisch GH: Chemosensitivity of prostate cancer cell lines and expression of multidrug resistance-related proteins. Eur J Cancer 35: 664-671, 1999. 